\title{
Primary Amyloidosis of the Renal Pelvis
}

\author{
G. D. CHISHOLM,* CH.M., F.R.C.S., F.R.C.S.ED. ; N. B. E. COOTER†, M.B., B.S.
}

J. M. DAWSON, $\ddagger$ M.A., M.B., M.R.C.P., D.M.R.D.

Brit. med. 9., 1967, 1, 736-738

Gross involvement of the pelvicaliceal system by primary amyloidosis is a distinct rarity. Rukavina et al. (1956) reviewed 142 cases of primary amyloidosis and showed that liver, spleen, myocardium, and kidneys were most often affected. Renal involvement occurred in $48 \%$ of their series; the glomeruli were invariably affected even in the earliest stages of the disease. and frequent involvement of the interstitial tissues and vasa rectae was recorded. In a more recent but smaller series Briggs (1961) reported similar findings and pointed out that renal lesions of primary and secondary amyloidosis were of similar distribution. Apart from the renal parenchyma, involvement of the urinary tract by primary amyloid is unusual and when it does occur it is most often seen in either the ureter or the bladder.

Clinically, primary renal parenchymal amyloid is manifest by proteinuria, the nephrotic syndrome, or renal failure.

The following two cases showed primary amyloidosis of the renal pelvis; both showed calcification on plain $x$-ray films and both developed renal failure, but this was due to pyelonephritis.

\section{Case 1}

A 66-year-old retired engineer first developed symptoms of malaise and dyspepsia in May 1964. Several months later he was nauseated and began to vomit. Apart from one episode of painless haematuria there were no other urological manifestations. The past history and family history were non-contributory. He was referred to Hammersmith Hospital in January 1965 after investigations had shown azotaemia (blood urea $230 \mathrm{mg} . / 100 \mathrm{ml}$.) and calcification in both renal areas. Physical examination revealed nothing of note except for hypertension (B.P. 190/110 mm. Hg). The urine contained pus cells, but cultures were sterile. Urine volumes were approximately $2.5 \mathrm{l}$. in 24 hours, with urinary urea concentration 600-700 $\mathrm{mg} . / 100 \mathrm{ml}$. There was no Bence Jones protein in the urine. Further investigations indicated chronic renal disease: blood urea $310 \mathrm{mg} . / 100 \mathrm{ml}$., potassium $6.1 \mathrm{mEq} / \mathrm{l}$., bicarbonate $19 \mathrm{mEq} / 1$., calcium $5 \mathrm{mEq} / \mathrm{l}$., and inorganic phosphate $4 \mathrm{mEq} / \mathrm{l}$. The haemoglobin was 8.4 g. and electrophoresis showed increased $\alpha_{1}$ - and $\alpha_{2}$-globulin, macroprotein, and $\gamma$-globulin (albumin $5 \mathrm{~g}$., globulin 3 g.). Rectal biopsy produced no evidence of amyloid. Plain $x$-ray films of the abdomen showed that over the medial half of each kidney there were well-developed moderately dense punctate patches of calcification which at their lower ends had a smooth contour marking the lower edge of the major caliceal systems (Fig. 1). There was no suggestion of a bony trabecular pattern, and both kidneys were smooth and of normal size. $X$-ray films of the hands, skull, spine, and chest showed nothing abnormal.

The patient's general condition was improved by restriction of protein and fluid, by blood transfusions, and by peritoneal dialysis. Two weeks later the right kidney was explored. The renal pelvis felt hard, but, when opened, gritty material was found to line the pelvis and calices and some of this was removed piecemeal. Histologically this material consisted largely of amyloid. The progress of the patient after this procedure showed little improvement, and

- Senior Urological Registrar and Tutor in Surgery, Hammersmith Hospital and Royal Postgraduate Medical School, London W.12.

t Registras in Morbid Anatomy, Hammersmith Hospital and Royal Postgraduate Medical School, London W.12.

‡ Registrar in Diagnosuc Radiology, Hammersmith Hospital and Royal Postgraduate Medical School, London W.12. though he was discharged home for a short period he soon returned and died from renal failure.

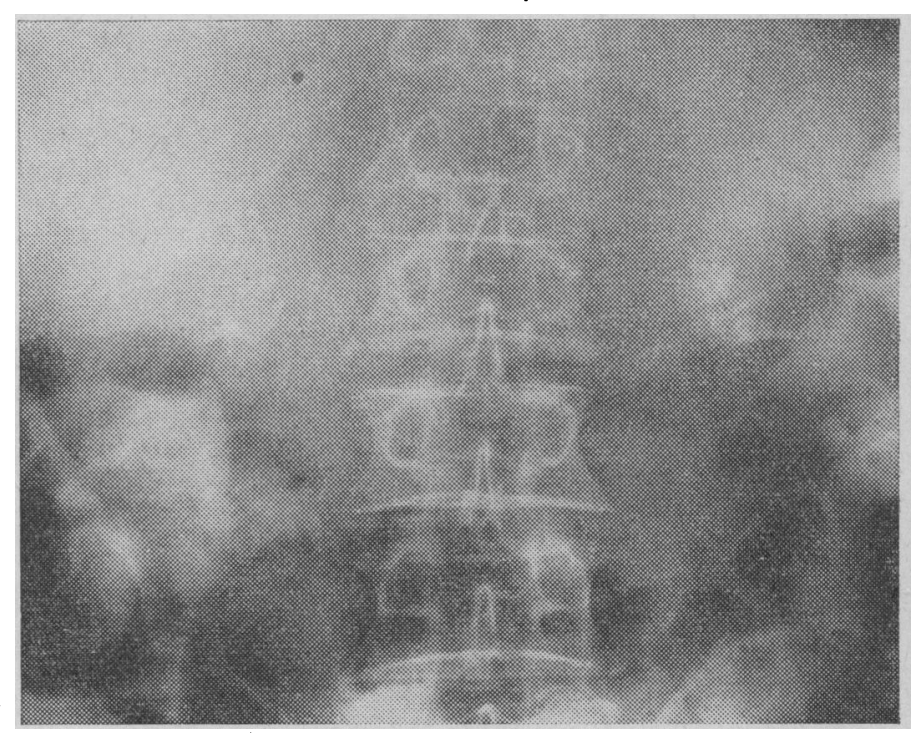

FiG. 1.-Case 1. Plain $x$-ray film of renal areas showing punctate areas of calcification outlining the renal pelves.

\section{Postmortem Findings}

Only the kidneys and heart showed any macroscopical abnormality.

Genitourinary System.-The kidneys appeared similar and were overweight (right 245 g., left 210 g.). The renal pelves and the proximal $1 \mathrm{~cm}$. of the ureters were enlarged and very firm, with an abrupt transition to normal distally (Fig. 2). On cross-section the renal pelves presented most unusual appearances. They were about $1 \mathrm{~cm}$. in thickness, firm and gritty in consistency, and sharply demarcated from the renal parenchyma ; they were amber in colour and contained many small cream-coloured foci up to $0.3 \mathrm{~cm}$. in diameter. Their inner surfaces were irregularly nodular with small superficial deposits of blood, fibrin, and pus. No recognizable epithelium was present. The lumen of the pelves was greatly reduced and almost occluded at the pelviureteric junction. The intrarenal parts of the renal pelves and caliceal systems were dilated and filled with pus and there was acute pyelonephritis.

Heart.-The epicardium contained two firm grey plaques, both approximately 2 by 1.5 by $0.5 \mathrm{~cm}$. overall, and there was a third plaque of similar appearance in the pericardium overlying one of the epicardial plaques. The heart was otherwise normal.

Microscopy.-Sections were stained with haematoxylin and eosin, van Gieson, Congo red, methyl violet, and thioflavine $T$ (Vassar and Culling, 1959). The epicardial plaques and sections of the renal pelvis contained heavy deposits of amyloid quite sharply demarcated from, and showing no significant involvement of, the adjacent myocardium or renal parenchyma. The amyloid from the renal pelvis showed foci of calcification (Fig. 3), a few bone spicules (Fig. 4), and rare foci of giant cells. The renal parenchyma showed severe acute pyelonephritis. No other evidence of amyloidosis was found ; in particular, sections of the heart, tongue, gum, rectum, and seminal vesicles were negative (Gross et al., 1930). There was no microscopical evidence of myeloma and, apart from the kidneys, no evidence of sepsis. Death was attributed to renal 
failure from severe pyelonephritis together with some degree of obstruction due to amyloid lining the calices.

\section{Case 2}

This patient had had her right kidrey removed in 1935 because of calculi. In 1961, when aged 58, she was found to be suffering from iron-deficiency anaemia and mild azotaemia (blood urea $59 \mathrm{mg} . / 100 \mathrm{ml}$.). Seven months later she developed an infection of the urinary tract which responded to antibiotics. A plain $x$-ray film of the abdomen showed a uniformly dense opacity in the left renal area indistinguishable from a staghorn calculus, overlying the middle and lower calices, with smooth edges outlining the major calices. There was no bony trabecular formation (Fig. 5). Excretion urography showed only faint excretion of contrast around the density. The left kidney was $13 \mathrm{~cm}$. long and its outline appeared smooth with no loss of cortex.

In January 1962 the left kidney was explored. There was a considerable degree of perinephritis and the pelvis was intrarenal. The kidney substance was split but no stone was found. The pelvicaliceal system was completely coated by a shell of calcified tissue ; a large amount of this material was removed and the kidney

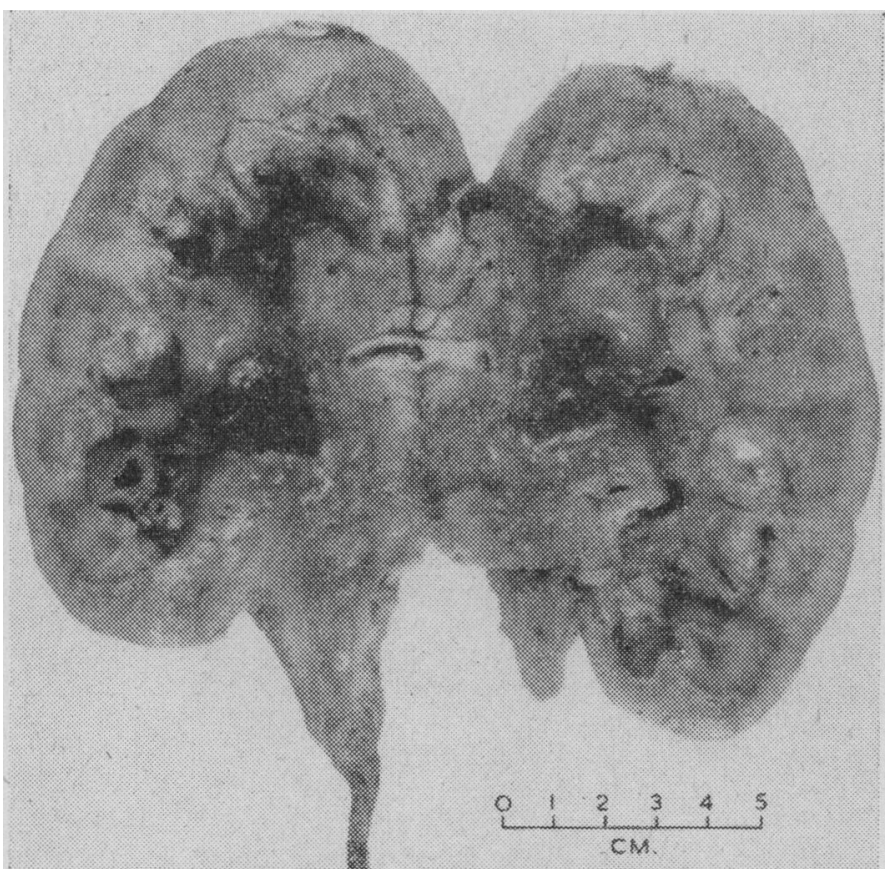

Fig. 2.-Case 1. Right kidney opened to show dilatation of the pelvicaliceal system and amyloid thickening of the pelvis extending into the pelvicaliceal junction.

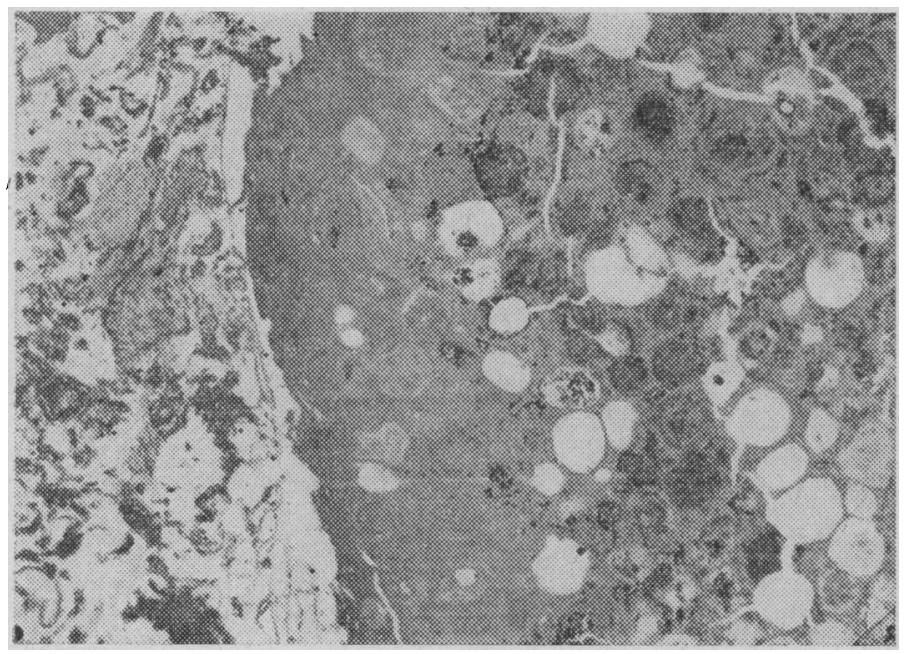

Fig. 3.- Case 1. Section of renal pelvis showing a large deposit of amyloid containing numerous dark specks of calcium on the right and adventitial tissues on the left. (H. and $E . \times 80$.) was drained by nephrostomy. The immediate postoperative progress was satisfactory, but a staphylococcal urinary infection developed and the blood urea rose steadily. Ten days after operation she was transferred to Hammersmith Hospital.

On admission she was somewhat dehydrated, was drowsy, and was vomitung. The blood urea was $450 \mathrm{mg} . / 100 \mathrm{ml}$., serum sodium $133 \mathrm{mEq} / 1$., potassium $6.5 \mathrm{mEq} / 1$., bicarbonate $14 \mathrm{mEq} / 1$., calcium $5.3 \mathrm{mEq} / \mathrm{l}$, and inorganic phosphate $5.4 \mathrm{mEq} / 1$. Though the urine output was difficult to assess because of leakage, the volume seemed adequate. After 14 days the blood urea had fallen to $49 \mathrm{mg} . / 100 \mathrm{ml}$. Three years later it was $68 \mathrm{mg} . / 100 \mathrm{ml}$. and she remained well.

Microscopy.-The tissues removed at operation consisted of small fragments of structureless material giving weakly positive reactions for amyloid when stained with methyl violet and Congo red but fluorescing strongly with thioflavine $T$.

\section{Discussion}

Case 1 presented several remarkable features. Both renal pelves were replaced by calcified amyloid which was visible radiographically and which was responsible for the death of the patient. Case 2 showed calcification of the renal pelvis of an entirely different character, radiologically indistinguishable from a staghorn calculus. It is possible that the right kidney, removed in 1935, was also involved by amyloid, but

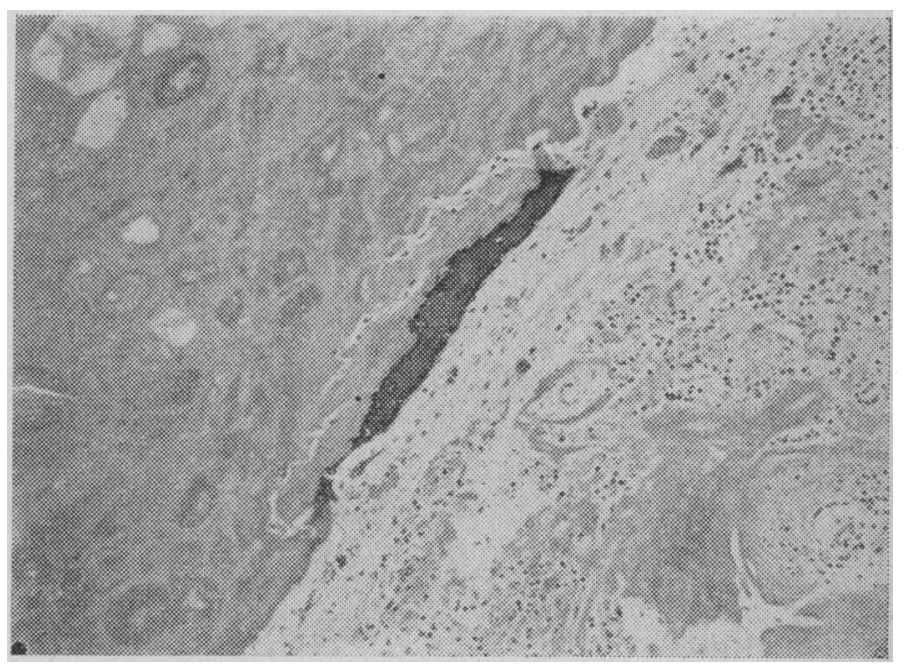

FIG. 4.-Case 1. Section of renal pelvis showing bony spicule at the edge of an amyloid deposit. ( $H$. and $\mathrm{E}$. $\times 80$.)

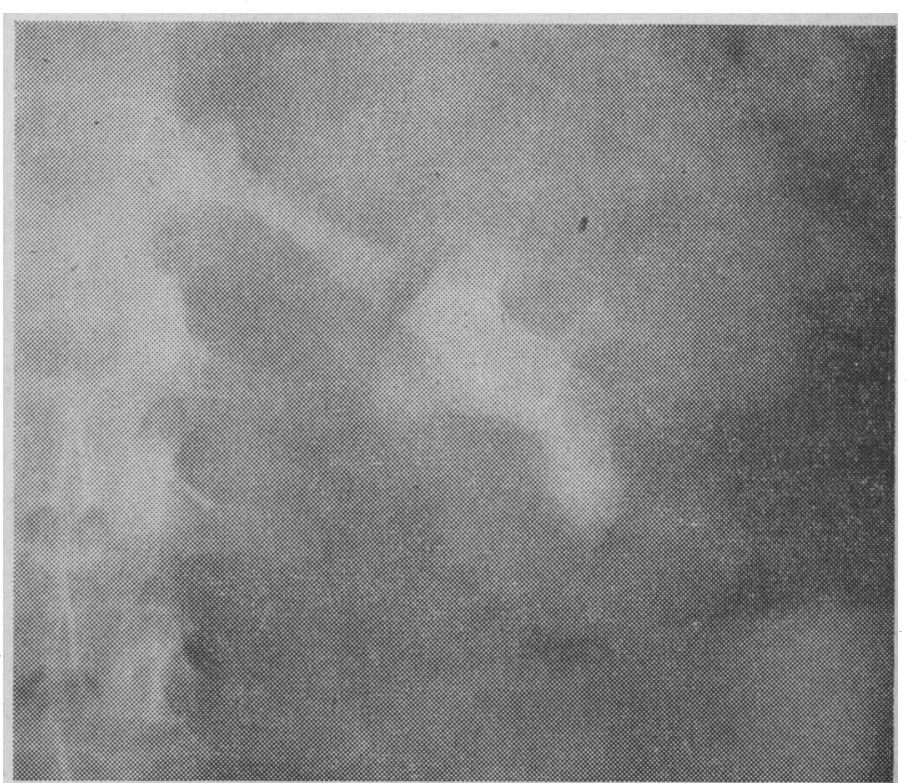

Fig. 5.-Case 2. Plain $x$-ray film of the left renal pelvis outlined by a uniformly dense cast of calcified amyloid. 
this can never be confirmed or refuted, since the specimen is not available. By contrast with the first patient, the second patient remained well and there were no manifestations of amyloidosis elsewhere.

Primary amyloidosis is distinguished from secondary by the absence of any known predisposing factors such as sepsis or multiple myeloma. It had been thought to occur mainly in the blood vessels and connective tissues, but many authors have emphasized that its distribution in some cases may be indistinguishable from secondary amyloidosis (Symmers, 1956; Rukavina et al., 1956). Primary amyloid may occur as a diffuse involvement of several organs, or sometimes it may be localized and appear as a few circumscribed deposits affecting one or two organs-for example, the pericardial deposits in Case 1. Primary amyloid tends to stain less reliably than secondary amyloid, but both types may show areas of calcification and ossification. A giant-cell reaction is infrequent in primary amyloidosis. Kinzel et al. (1961) and Grace and Walton (1964) reported localized deposits of primary amyloid in the bladder in 30 cases; Lehmann (1937) and Johnson and Ankenman (1964) recorded primary amyloid of the ureter in a similar number. There have been occasional reports of localized involvement of the urethra (Albertini, 1925 ; Ullmann et al., 1964) and prostate (McDonald and Heckel, 1956), and it has been suggested that involvement of the seminal vesicles may be more common than was previously thought (Goldman, 1963).

We are aware of only three cases of primary amyloidosis localized to the renal pelvis. Akimoto (1927) described warty nodules of amyloid in both hydronephrotic pelves but did not mention calcification in a patient who had died of renal failure. Gilbert and McDonald (1952) reported a case of left hydronephrosis with no radiographic or histological evidence of calcification. There was amyloid in the lower calix, the inferior portion of the renal pelvis, and the adjacent $3 \mathrm{~cm}$. of ureter. In the third case (Sato, 1957) there was no abnormal calcification, but retrograde pyelography showed irregular filling defects of the renal pelvis and ureter suggestive of tumour. The specimen showed amyloid of the renal pelvis and upper ureter.

In these three cases and our two there has been no planned approach to the management of the condition, as the diagnosis was not known, nor indeed suspected, at the time of operation. Gilbert and McDonald (1952) and Sato (1957) made the diagnosis on examining the nephrectomy specimen. Akimoto's case was diagnosed at necropsy. In Case 1 the diagnosis was known in life but the combined effect of pyelonephritis and obstruction by amyloid was fatal ; in Case 2 the encouraging result after exploration of the solitary kidney would indicate that removal of as much of the material as possible is worth while and should be attempted.

Calcification and ossification are not unusual in primary amyloid deposits, and large amounts have occurred in the pancreas (Pocock and Dickens, 1953) and near the sphenoid (Bauer and Kuzma, 1949); periureteric osseous metaplasia with formation of well-defined bone trabeculae has also been described (Higbee and Millett, 1956), but only the deposits in the pancreas were seen on $x$-ray examination. The radiological demonstration of amyloid in the bladder has not been recorded. Radiological calcification of the pelvicaliceal system from any cause is not common. Destructive or degenerative lesions of the kidney may be associated with metastatic or dystrophic calcification (Salik and Abeshouse, 1962) ; patchy calcification may also occur with a branched calculus, renal tuberculosis, nephrocalcinosis from whatever cause, renal tumour or abscess, small calcified cysts, bilharzia, sponge kidney, chronic pyelonephritis, papillary carcinoma of the pelvis, leucoplakia of the pelvis, or old Thorotrast administration. Of these, old Thorotrast pyelography, renal tuberculosis, leucoplakia, and possibly bizarre renal calculi most closely resemble the radiological appearances in our two cases. Thorotrast was used for retrograde pyelography, particularly in Germany, prior to 1939 , and radiographic appearances remarkably similar to those in Case 1 have resulted from this material lodging within areas of renal parenchymal damage (Eschbach, 1942 ; Hartig and Neideck, 1963).

Radiographically our two cases did not show any particular features which might have been taken as characteristic of amyloidosis: in Case 1 the calcification conformed exactly to the caliceal shape ; in Case 2 it did not extend into the renal parenchyma and was indistinguishable from a large calculus. In our view the radiographic appearances of primary amyloidosis of the renal pelvis have no special characteristics, so that the diagnosis can only be suspected.

\section{Summary}

Two cases of primary amyloidosis of the renal pelvis are described. In the first there was unusual radiological calcification of the pelvicaliceal system of both kidneys and the patient died from renal failure. In the second the density of the radiological calcification in the pelvis of a solitary kidney closely resembled a calculus; this patient remained well. Exploration of the kidney in both cases showed calcific material lining the pelvicaliceal system. It is suggested that any unusual calcific debris in a renal pelvis should be examined for amyloid.

We wish to thank Professors C. V. Harrison, R. E. Steiner, and Ralph Shackman for their assistance with this report; both cases were under the care of Professor Shackman. We are also indebted to Dr. C. H Wrigley, Department of Pathology, Royal Hampshire County Hospital, Winchester, for permission to report the sections from Case 2 ; and to the Department of Medical Illustration at the Royal Postgraduate Medical School for the figures.

\section{REFERENCES}

Akimoto, K. (1927). Beitr. path. Anat., 78, 239.

Albertini, A. von (1925). Frankfurt Z. Path., 33, 248

Bauer, W. H., and Kuzma, J. F. (1949). Amer. F. clin. Path., 19, 1097

Briggs, G. W. (1961). Ann. intern. Med., 55, 943.

Eschbach, H. (1942). Fortschr. Röntgenstr., 66, 207. 137.

Goldman, H. (1963). Arch. Path., 75, 94.

Grace, D. A., and Walton, K. N.' (1964). 7. Urol. (Baltimore), 92, 655

Gross, L., Antopol, W., and Sacks, B. (1930). Arch. Path., 10, 840.

Hartig, W., and Neideck. J. (1963). Z. Urol., 56, 249.

Higbee, D. R., and Millett, W. D. (1956). \%. Urol. (Baltimore), 75, 424

Johnson, H. W. and Ankenman, G. J. (1964). Ibid., 92, 275.

Kinzel, R. C., Harrison, E. G., and Utz, D. C. (1961). Ibid., 85, 785.

Kinzel, R. C., Harrison, Zbl. all, Path. path. Anat., 68, 209.

Lehmann, G. (1937. Heckel, N. J. (1956). f. Urol. (Baltimore), 75, 122

Mocock, D. S., and Dickens, J. (1953). New Engl. \%. Med., 248, 359.

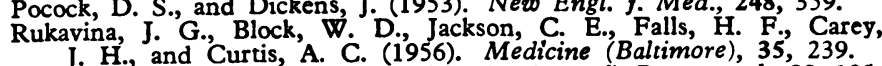

Salik, J. O., and Abeshouse, B. S. (1962). Amer. F. Roentgenol., 88, 125.

Sato, A. (1957). Acta med. biol. (Niigata), $5,15$.

Symmers, W. St. C. (1956). F. clin. Path., 9, 187. 9 . Urol. (Baltimore), 92, 42 .

Vassar, P. S., and Culling, C. F. A. (1959). Arch. Path., 68, 487. 